years of the chorea to 11.3 per cent. and in six years to 20 per cent. In the Report of the Collective Investigation Committee of the British Medical Association on Chorea, 1887, under heading 16, "The Occurrence of Rheumatism during or immediately subsequently to the Attack of Chorea," it is found that 56 out of 439 cases, or 12.7 per cent., suffered from rheumatism during or immediately subsequently to the attack of chorea, but in only 26 of these cases was the attack of rheumatism the first attack-i.e., in a little under 6 per cent. The following table is a summary of the above 115 cases :-

\begin{tabular}{|c|c|c|c|c|}
\hline Date. & No rheu & $\underbrace{\text { matism. }}_{\text {Per cent. }}$ & Number. & $\overbrace{\text { Per cent. }}^{\text {latism. }}$ \\
\hline $\left.\begin{array}{l}\text { On admission (from Janu- } \\
\text { ary, 1892, to June, 1894)... }\end{array}\right\}$ & 78 & $67 \cdot 8$ & 37 & $32 \cdot 2$ \\
\hline Three years later (July, 1895) & 65 & $56 \cdot 5$ & 50 & $43 \cdot 5$ \\
\hline Three years later (July, 1898) & 54 & 47 & 61 & 53 \\
\hline
\end{tabular}

Some objections may be lodged against the above figures since in a considerable number of the cases no evidence could be obtained; these cases have been counted with the non-rheumatic and can only tend to lower the percentage of cases in which rheumatism subsequently occurred.

Harley-street, W.

\section{A NEW METHOD OF RESTORING THE ABSENT FUNCTION OF MUSCLES IN INFANTILE PARALYSIS.}

\section{By N OBLE SMITH, F.R.C.S. EDIN.,}

SURGEON TO THE CITY ORTHOPADIC HOSPITAL AND SURGEON TO ALI SAINT'S' CHILDREN'S HOSPITAL, LONDON.

ALL orthopædic surgeons know that in cases of muscular contraction associated with infantile paralysis - as, for instance, when the calf muscles are contracted and their antagonists, the flexors of the foot, are paralysed-division of the tendons of the contracted muscles is generally followed by improvement in the nutrition of the whole foot. In such a case as I have suggested division of the tendo Achillis not only permits restoration of the foot to a natural position, but it also frequently brings about an increased warmth of the skin and subcutaneous tissue and presumably of the paralysed muscles also. Very little notice has been taken of this improvement in nutrition and when noticed at all the result has generally been attributed to the increased movements of the parts which the release of the contraction has permitted. This explanation does not seem satisfactory for the following reasons. I have found that the almost immediate effect of tenotomy of the tendo Achillis, with as much reduction of the deformity as possible at the time of operation, has set up a distinct increase in warmth of the part the day after operation. This increase in warmth has continued permanently, or at least if it has subsided slightly after a few days yet it has remained distinctly apparent during the period of from two to three weeks or more whilst the foot has been kept absolutely quiescent, and the warmth has continued afterwards as a permanent benefit. Mr. William Adams referred to this subject in his post-graduate lectures published in 1893. He stated that the result s' might be due to a certain amount of muscular action taking place in the muscles not contracted, after the tendons of the contracted muscles had been divided." But he remarked that Dr. Brown-Séquard, to whom he mentioned the occurrence, had said that he "believed it to be due to a direct reflex action of the spinal cord, and that a local increase of temperature probably followed all surgical operations, but it would be most observable in cases of paralysis."

We know well that additional warmth, whether produced by external heat or by friction, massage, stimulating liniments, or by any other means, has a beneficial effect upon a paralysed limb, and will help materially in restoring the functions of the paralysed muscles. That is to say, if a muscle is not completely and absolutely paralysed, or perhaps it would be more correct to say that if the nerve-supply of a paralysed muscle or muscles as well as the muscles themselves is capable of improvement, additional warmth of the part will greatly assist in such restoration of power. This being so, it is not surprising that, whatever may be the explanation of the increased warmth following the tenotomy, the result of such increased temperature must act beneficially upon the paralysed parts. Further, it seems probable from the rapid improvement in function of the neighbouring muscles which sometimes occurs that some more direct influence upon the nerves or muscles must take place. After tenotomy of a contracted muscle, in cases in which other muscles have been so far paralysed that they have been beyond the possibility of amelioration, there has yet been a permanent improvement as regards warmth and nutrition. In many instances where the limbs have been cold, blue, and with a tendency to ulceration these symptoms have to a great extent disappeared and almost invariably the skin has lost its blueness.

Operation on the paralysed muscles. - The idea occurred to me that if tenotomy of a sound muscle was capable of producing so much improvement in nutrition in a neighbouring muscle weakened by paralysis, how much more direct an influence would tenotomy of the affected muscle itself have. Acting upon this idea I have operated in this way on two patients whose histories I will now record.

CASE 1.-A girl, aged seven years, was brought to me on Nov. 10th, 1897. Two years and three months previously she had been suddenly attacked by infantile paralysis. There was said to have been complete motor paralysis from the waist downwards, but this began to pass away rapidly, so

FIG. 1.

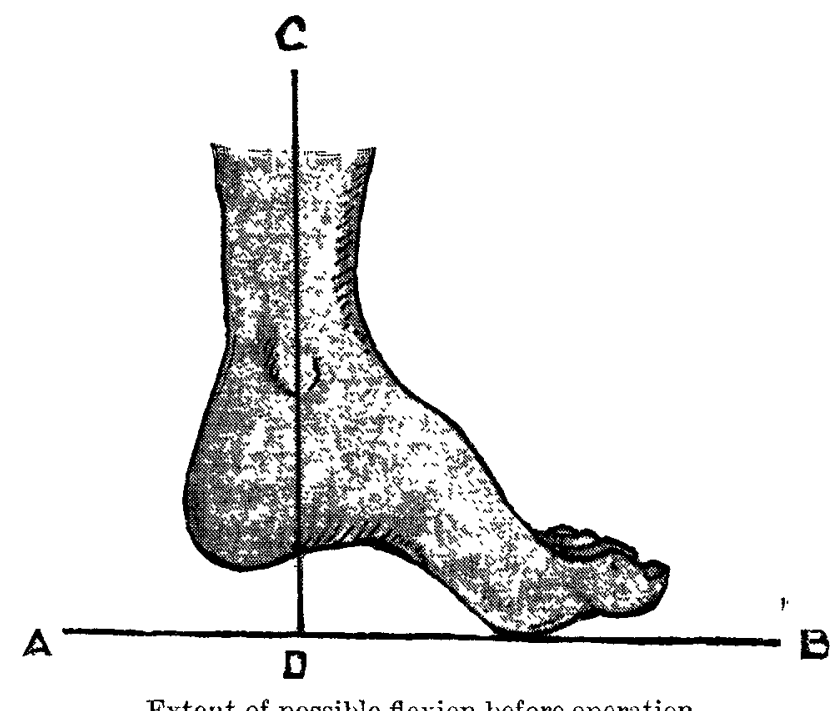

Extent of possible flexion before operation.

that in less than a week the patient was able to sit up. The functions of the bowels and bladder were very feeble at first but became normal at the end of five days; sensation was perfect from the first. She had been under the care of Dr. Suckling of Birmingham and had been treated by massage and electricity. At the time of my examination I found the left leg feeble in all its movements, the extensors of the toes

FIG. 2.

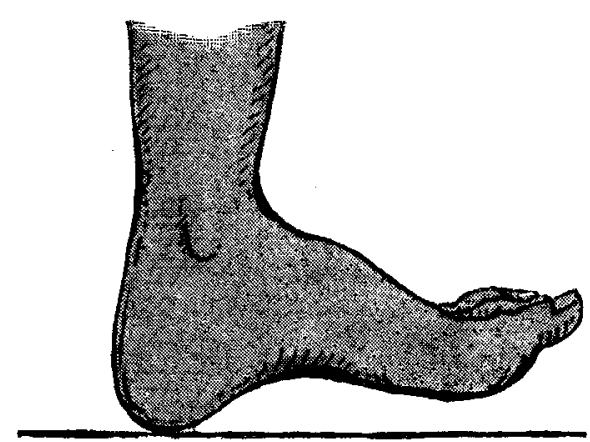

Extent of pcssible flexion after operation.

(flexors of the ankle) were apparently entirely paralysed, and there was contraction of the calf muscles, so that in walking the heel did not touch the ground. The left leg (measured at the internal malleolus) was $\frac{1}{3}$ in. shorter than the right, and when the foot was flexed as much as the contraction 
would permit there were $1 \frac{1}{4}$ in. between the heel and the ground, as indicated by the line A B at right angles with the vertical axis C D of the leg and on a level with the ball of the great toe, as shown in Fig. 1. The right leg was quite strong, all the muscles acting well. Before operating I requested Dr. Risien Russell to see the patient and he reported as follows: "All the muscles of the left leg respond to Faradaism with the exception of the tibialis anticus and extensor longus digitorum, neither of which muscles respond even to a painful current, and one which when applied to the motor points of these anterior muscles results in marked contraction of the soleus and gastrocnemius on the posterior aspect of the limb. All the muscles which respond to Faradaism also react to galvanism, K.C.C. being greater than A.C.C.; but in the anterior tibial group only an exceedingly feeble response is obtained (A.C.C. greater than K.C.C.) with a very strong current, and one which, applied to the anterior aspect of the limb, evokes marked contraction of the soleus and gastrocnemius. The examination thus shows that there is most pronounced reaction of degeneration in the tibialis anticus and extensor longus digitorum, while the quality of the response from the other muscles of the leg is normal." On Nov. 12th I divided the tendo Achillis of the affected leg; I also divided the tendons of the tibialis anticus, extensor proprius pollicis, and extensor longus digitorum. In the case of the latter muscles, which were considered to be paralysed, there was some difficulty in isolating their tendons. On the 20th I removed the bandage and tried the action of the foot. Upon directing the patient to try to move her foct there was distinct movement of the tendons of the muscles which had previously seemed paralysed. Being so soon after the operation I did not allow more than the slightest effort to be made by the patient. On the 24th Dr. Risien Russell again examined this patient and verified the fact of this restoration of muscular power. The patient made an excellent recovery and has since been walking about with a light temporary support.

One cannot imagine that after two years and three months from the time of the attack of infantile paralysis, seeing that the reaction of degeneration was present, it would

Fig. 3.

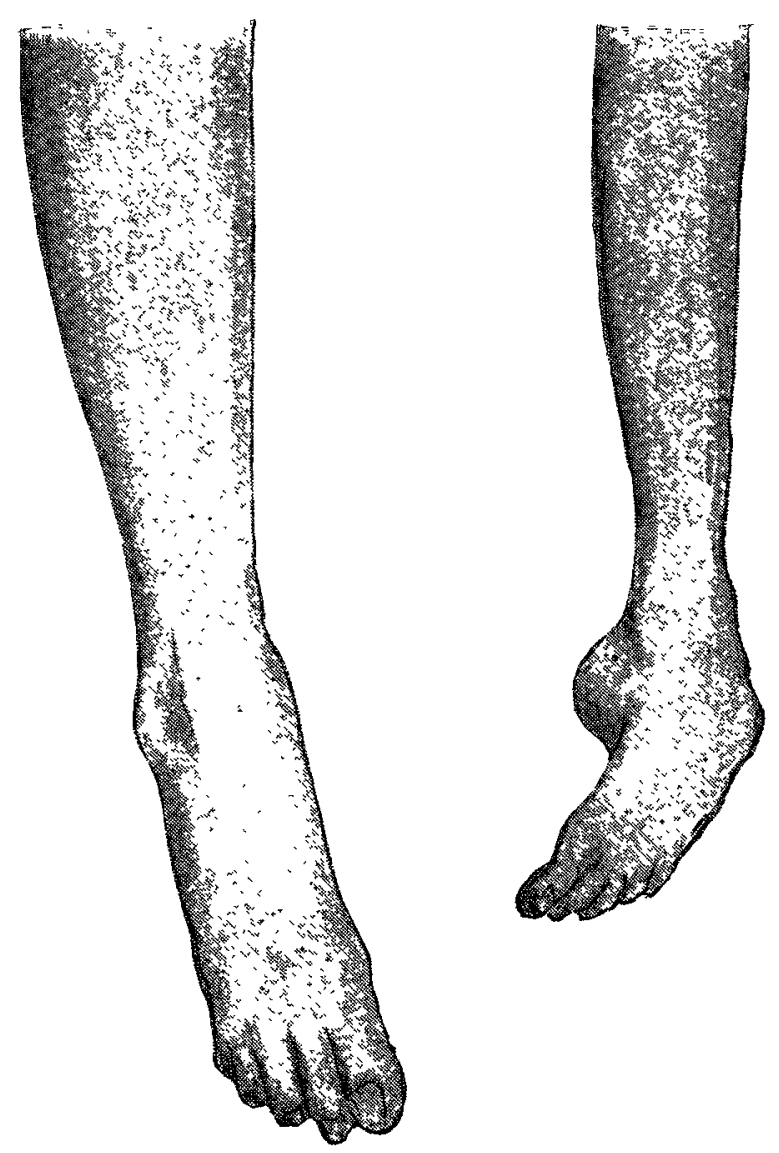

Showing the size of the paralysed leg in ecmparison with that of the sound one.

have been possible, under any ordinary treatment, to obtain restoration of function. Therefore I think we may assume that the operation upon the tendons of the paralysed mis.les was the direct means of restoring that cower.

CASE 2.-On Nor. 21st, 1895, a girl aged eleven years, was first brought to me. She had suffered from an attack of infantile paralysis at the age of three months and had been subsequently operated upon for contraction of the calf muscles. I was told that during recent years she had got very much worse as regards ability to get about, the left leg being almost useless to her. The left leg was much smaller than the right and deformed, as shown in Fig. 3 , and the patient was unable to extend the foot beyond the position there shown. Two years previously to her visit to me she had giren up wearing iron supports and the foot had been getting much more deformed. I found there was $2 \frac{1}{4}$ in. shortening of the limb, measuring from the heel to the ground, and the leg below the knee was very cold and blue. The extent of the paralysis was as described below. By means of apparatus she was enabled to walk about with comparative comfort and I only saw her at long intervals. On Oct. 22nd, 1896, I divided a band of the internal lateral ligament which held the foot in the varus position and I was then able to lessen the amount of deformity considerably. On Nov. 3rd, 1897, the patient was walking better, but $I$ found the foot and the lower half of the leg very cold and the circulation very feeble. Ulcers were almost constantly forming and healing up again. As so much benefit in position had been obtained by the cutting of the lateral ligament I thought it worth while to operate

\section{FIG. 4.}

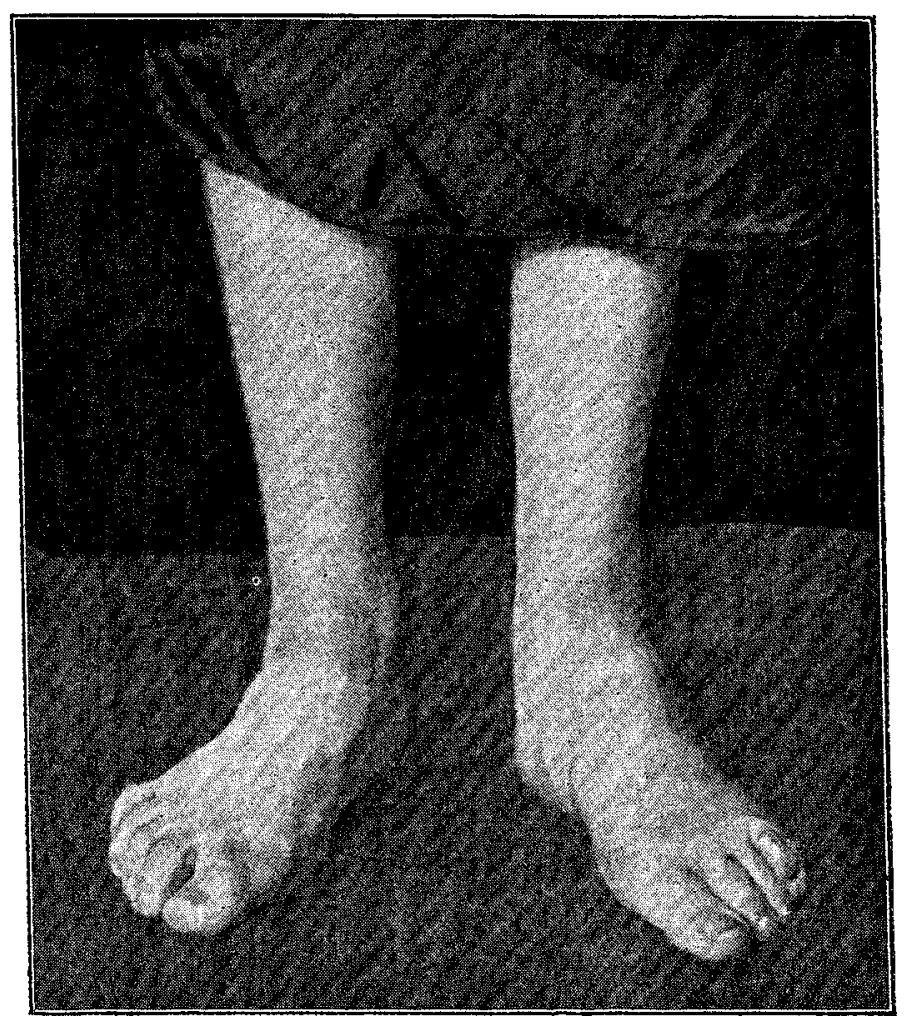

Present condition, both feet resting flat on the ground.

on the tendo Achillis and at the same time to divide the tendons of the paralysed muscles. I asked Dr. Althaus to examine the patient first and he reported as follows: "Nov. 3rd, 1897.-1. N. tibialis. (a) Fraradaism.-No response on application to the nerve at the back of the kneejoint or to the motor points of the gastrocnemius, soleus, plantaris, flexor digitorum communis, and flexor hallucis longus. (b) Constant current.--Anodic opening contraction (A.O.C.) absent up to 15 milliamnères in the nerve and muscles above mentioned. Kathodic closing contraction (K.C.C.) slightly present between 10 and 15 milliampères. A few voltaic alternatives cause this response to be diminished. 2. $N$. peroneus. (a) Faradaism.-Fair response with 8 R. A. Stower's induction coil on the nerve, and on the motor points of the peroneus longus and brevis, the extensor digitorum communis, the tibialis anticus, extensor hallucis longus, and the interossei dorsales. (b) Constant ourrent.Slight A.O.C. on application to the nerve and the motor points of the muscles, and stronger K.C.C. in the same, with 10 milliampères." In operating I divided the tendo Achillis (muscle acting soundly and the tendons of the tibialis anticus, extensor proprius pollicis and the extensor longus digitorum (apparently paralysed), and I also broke down some very firm adhesions which prevented the free movement of the tendo Achillis. On Nov. 24th, three weeks after the operation, I found the leg and foot quite warm, the foot 
in excellent position, and a great improvement in the action of the muscles." Dr. Althaus reported again as follows : "Nov. 24th, 1897. - Farado-muscular response increased in the sphere of the peroneal nerve, especially tibialis anticus, extensor digitorum, and extensor hallucis longus. No other marked change." Her present condition, Oct. 5th, 1898, is as follows (Fig. 4). The patient is now able to walk about with only a very slight limp and suffers no inconvenience. She wears a light apparatus to take the place of the weak anterior muscles and only requires $\frac{1}{4}$ in. extra thickness on the heel and sole of the left boot. The foot and leg are well nourished and she has never suffered from chilblains or ulcers since the last operation. Dr. Althaus saw her this day and reported that "the leg seems altogether better. Electricaliy less current strength is required to cause muscular action."

It will, of course, require far more experience than that derived from the above cases to enable us to form a fair estimate of what may be expected from division of the tendons of paralysed muscles. It is obvious that such a procedure cannot be expected to restore action in muscles which have become absolutely degenerated, nor can we expect paralysed nerves to be capable of regaining their function. It seems certain, however, that the significance of what is called the "reaction of degeneration" must be modified, for it would appear that this symptom does not prove that no power of recovery exists. The results in the two,cases recorded above are so definite that I cannot see any other explanation of the benefits derived than that suggested. The advantages are obvious and great. In the first case it means the difference between the child being absolutely cured in a few months and having to wear some mechanical support for the rest of her life. In the second case, although some weakness remains, yet the improvement is very considerable, and I would further point out that this improvement is distinctly more than could be expected as the result only of making the joint more free. I could record other cases in which apparently similar results have been obtained, but as no electrical examination was made before operation I prefer to limit my report to the above two instances.

Queen Anne-street, w.

\section{Clinital Altes:}

\section{MEDICAL, SURGICAL, OBSTETRICAL, AND THERAPEUTICAL.}

\section{A RARE, IF NOT UNIQUE, FRACTURE OF THE TIBIA.}

By LeONaRd Molloy, M.A., M.D. Dub.,

HOYORARY SURGEON TO THE VICTORIA HOSPITAL, BLACKPOOL.

THE patient was a man, aged sixty-five years. On Hay 19th, 1897, while getting into his cart with his right foot on the step his pony started. He endeavoured by hopping along on his left foot to keep pace with the pony and so clamber into the vehicle, but while so doing he fell away from the trap on to his left side. He felt that he had sustained an injury to his left knee and found that he could not stand. He was removed to hospital where he came under my care. The knee-joint was enormously swollen and it was exceedingly difficult to localise the injury, but I came to the conclusion that there was an almost vertical fracture through the head of the tibia, opening, of course, into the joint, and that the greater part of the external tuberosity, with the fibula attached to it, was separated from the head of the bone. There was no fracture of the fibula. The difficulty of diagnosis was increased by the fact that there was shortening of the affected limb to the extent of $1 \frac{1}{2} \mathrm{in}$., but this I was enabled to satisfy myself was due to a fracture of the left femur which the patient had sustained in childhood and for which he had beeu treated in Genoa. The limb was put up on a Lawrence's back splint and so treated throughout. An attempt was made to take a radiogram of the injury before the effusion into the joint had subsided, but it was unsuccessful. Later, however, a radiogran was taken by Mr. T. D. Whittington of this town, of which a reduced reproduction of the photographic print is annexed. The photographic plate was placed behind the knee. From measurements made on the original radiogram it appears that the fracture ran from a point on the articular surface of the head of the bone, $2 \frac{1}{2}$ in. from the internal border of the internal tuberosity, almost directly downwards for 2 in., when it came flush with the shaft of the bone and so separated the major portion of the external tuberosity. This fragment could be moved antero-posteriorly, when the resulting crepitus gave one the idea of two broad surfaces rubbing one upon the other. I am quite sure that there was

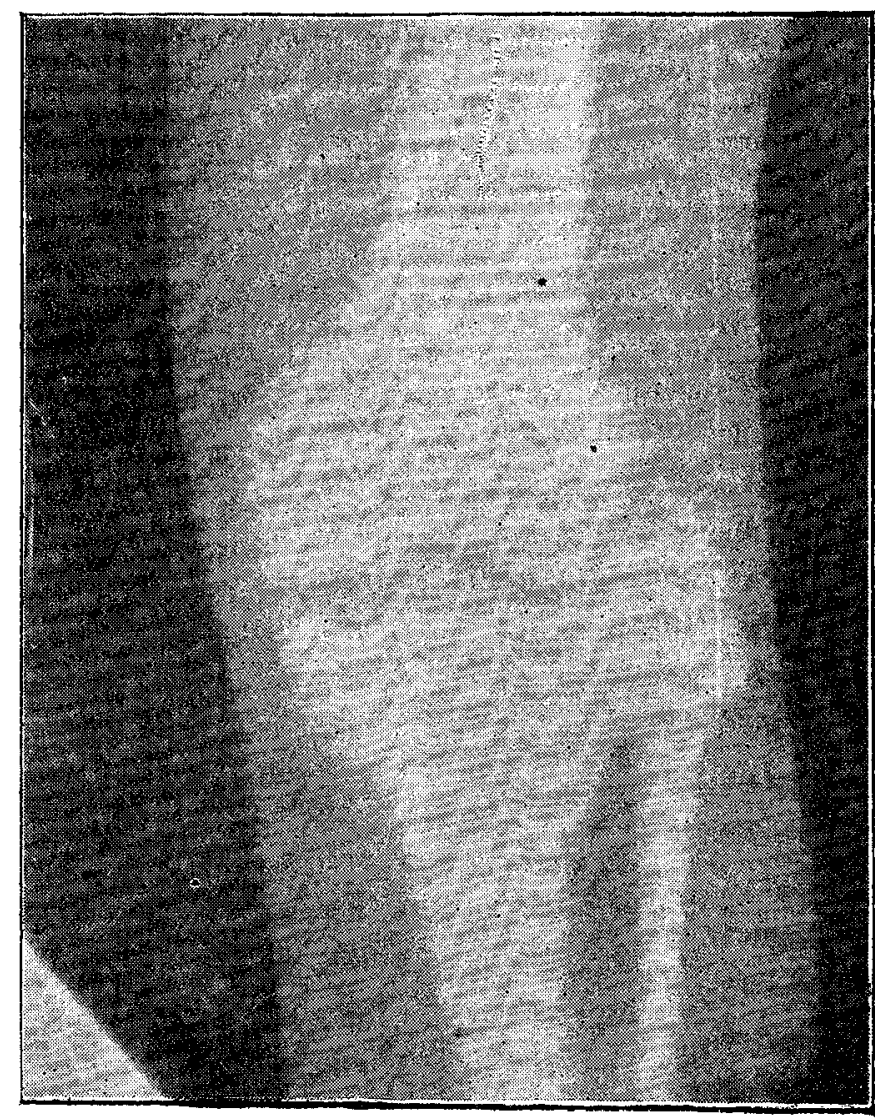

Radiogram showing deformity of head of tibia resulting from fracture.

no other line of fracture in the head of the bone. Heyden. reich's plate of an injury to the "head of the tibia with division of the superior extremity into many pieces" shows a $\boldsymbol{W}$-shaped line of fracture, one of the limbs of which takes exactly the line which, I believe, was present in the above case, the cause being, as in this, concussion of the tibial head by the femoral condyles. I am unable to find a record of a similar case to the above. The patient is now able to walk as well as he did before the accident. On measurement with callipers I found that there was broadening of the head of the tibia from side to side to the extent of $\frac{3}{4}$ in.

Blackpool, Lanes.

\section{SUCKLING A CAUSE OF ABORTION.}

By 'T. M. Callender, M.B., C.M. Edix., LATE RESIJENT SURGEON ROYAL MATERNITY AYD SIMPSON MEMORIAT HOSPITAL, EDIXBURGH.

I THINK the following case of abortion of interest on account of the cause which I attributed it to-viz., suckling.

The patient, a woman, aged about thirty years, who had had five children, was well-developed, strong, and healthy, with nothing abnormal in her previous menstrual history. There was no history of endometritis or of specific illness. Her first child was born seven years ago and her last twelve months ago. All her labours were normal except the last but one, when the child was stillborn. It was a breech presentation and there had been some ante-partum hæmorrhage two months before birth. There were no previous iniscarriages. Since the last child was born she had one menstrual period, three months ago; she missed the next period and at the date when she should have had her third period she began to suffer from uterine pains and hæmorrhage. She had suffered from morning sickness during the last month. Her breasts were large and full of milk, which was watery in 